\title{
KEBUTAAN OLEH KARENA PRIMARY ANGLE CLOSURE GLAUCOMA PADA RUMAH SAKIT UMUM PUSAT SANGLAH DENPASAR
}

\author{
Satya Nugraha $^{1}$, Agus Kusumadjaja ${ }^{2}$ dan Ari Andayani ${ }^{3}$ \\ Program Studi Pendidikan Dokter, Fakultas Kedokteran, Universitas Udayana, Denpasar, Indonesia \\ E-mail: dwisatyan@gmail.com
}

\author{
ABSTRAK \\ KEBUTAAN OLEH KARENA PRIMARY ANGLE CLOSURE GLAUCOMA PADA \\ RUMAH SAKIT UMUM PUSAT \\ SANGLAH DENPASAR
}

\begin{abstract}
Primary Angle Closure Glaucoma adalah salah satu jenis glaucoma yang bisa menyebabkan penderitanya mengalami kebutaan. Kebutaan bisa terjadi karena adanya tekanan intraokular (TIO) di dalam bola mata yang tinggi akibat cairan aquos humor tidak dapat keluar karena canalis schlem terhambat (sudutnya menutup). Di Indonesia banyak terjadi kasus Glaukoma Primer Sudut Tertutup, karena itu dibuatlah penelitian karena angka kejadian yang tinggi. Penelitian ini merupakan suatu penelitian deskriptif cross sectional dimana sumber data berasal dari data sekunder yaitu rekam medis pasien penderita Glaukoma Primer Sudut Tertutup. Pengambilan data dilakukan dengan metode total sampling bertempat di Instalasi Rekan Medis. Distribusi variabel penelitian meliputi usia, jenis kelamin, tekanan intra okular. Analisis data di paparkan dalam bentuk tabel dan narasi. Dari 211 sampel yang ditemukan mengalami Glaukoma yang terdata di Ruang Rekam Medis Rumah Sakit Umum Pusat Sanglah, pasien Glaukoma didominasi oleh usia 60-69 tahun yaitu 71 orang $(31,0 \%)$, dengan jenis kelamin laki-laki lebih banyak yaitu $112(51,9 \%)$ orang dibandingkan perempuan 99 orang $(48,1 \%)$, dan lebih banyak TIO diatas nilai normal baik pada mata kanan maupun mata kiri yaitu 124 orang $(64,6 \%)$ dibanding TIO normal 87 orang $(35,4 \%)$. Untuk jumlah kebutaan adalah 96 orang, didominasi oleh pasien dalam rentang usia 60 - 69 yaitu 39 orang. Pada kelompok jenis kelamin didapatkan kebutaan lebih banyak pada perempuan dengan 58 orang. Kebutaan terlihat lebih banyak dengan peningkatan tekanan intraokuler yaitu 71 orang.
\end{abstract}

Kata kunci: Kebutaan, Glaukoma Primer Sudut Tertutup, Faktor Risiko

\section{ABSTRACT \\ BLINDNESS BECAUSE OF THE PRIMARY OPEN ANGLE GLAUCOMA IN SANGLAH GENERAL HOSPITAL DENPASAR}

Primary Angle Closure Glaucoma is one kind of Glaucoma that can cause blindness to the patient. Blindness can happen because there is high Intra Ocular Pressure (IOP) inside the eyes ball. This is because Aquos Humor Liquid cannot get out from the eyes because the canalis schlem is obstructed (closed angle). In Indonesia there are many cases of Primary Angle Closure Glaucoma, which is why this research is conducted because of the high incident number. This research is a cross sectional descriptive study where the source of the data comes from secondary data, namely medical records of patients with Primary Angle Closure Glaucoma. Data retrieval is done by total sampling method located at Medical Associate Installation. The distribution of research variables included age, gender, Intra Ocular Pressure. Data analysis is described in the form of tables and 
narratives. From 211 sample that found having Glaucoma and registered in medical record room, is dominated by the age of 60-69 years with 71 people (31.0\%), male is higher with 112 people (51.9\%) than female 99 people (48.1\%), high intraocular pressure is higher with 124 people $(64.6 \%)$ than normal intraocular pressure on both eyes in 87 people (35.4\%). For the blindness is dominated by age 60-69 years in a total of 39 people. From the sex group, female is higher in a total of 58 people. High intraocular pressure is higher than normal in a total of 71 people.

Keywords: Blindness, Primary Open Angle Glaucoma, Risk Factor 


\section{PENDAHULUAN}

Kebutaan merupakan suatu masalah kesehatan di dunia, dilaporkan bahwa terdapat lebih dari 50 juta orang buta di dunia saat ini, termasuk di Asia yaitu sekitar 20 juta dan di Afrika sekitar 6 juta. Salah satu penyebab kebutaan ini adalah Glaukoma, yaitu merupakan penyebab kebutaan nomor tiga di dunia setelah katarak dan kelainan refraksi. Menurut website WHO, diperkirakan jumlah kasus kebutaan akibat glaukoma adalah 4,5 juta, atau sekitar $12 \%$ dari seluruh kebutaan (WHO 2009). Glaukoma bisa dikategorikan menjadi glaukoma primer, glaukoma sekunder dan glaukoma congenital. Penelitian prevalensi glaukoma di berbagai negara menunjukkan sebagian besar glaukoma merupakan glaukoma primer, yaitu glaukoma sudut terbuka (Primery Open Angle Glaucoma) yang proporsinya paling banyak, diikuti glaukoma primer sudut tertutup (Primary Angle Closure Glaucoma) (Quigley \& Broman 2006; Shen et al 2008). Primary Angle Closure Glaucoma (PACG) adalah adanya tekanan intraokular (TIO) di dalam bola mata yang tinggi akibat cairan aquos humor tidak dapat keluar karena canalis schlem terhambat (sudutnya menutup). Pada tahun 2010, perkiraan prevalensi PACG di seluruh dunia adalah 15,7 juta dengan hampir $25 \%$ kasus yang mengakibatkan kebutaan. PACG lebih sering terlihat pada laki-laki dan kelompok etnis tertentu yaitu lebih tinggi di Inuits, Asia Timur dan kelompok etnis campuran di Afrika Selatan. Tingkat PACG di antara Inuits yang berusia lebih dari 40 tahun adalah 2,1\% - 5,0\% dan $0,4 \%-1,3 \%$ di antara orang Asia Timur. Etnis di Kaukasia 0,1\% - 0,6\% dan Afrika 0,1\% - 0,2\% (American Academy of Ophthalmology Glaukoma 2013). Risiko terjadinya PACG, progresifitas penyakit dan kebutaan yang diakibatkannya dihubungkan dengan berbagai faktor risiko. Selain tingginya tekanan intraokular, faktor risiko lainnya antara lain adalah ras, jenis kelamin, usia, jenis/tipe glaukoma, adanya riwayat glaukoma dalam keluarga dan riwayat pengobatan yang didapatkan. Gejalanya meliputi nyeri mata berat datang tiba-tiba, pandangan kabur, terlihat halo (lingkaran) saat melihat objek, mata merah, lunak dan mengeras karena tekanan meningkat. Prinsip pengobatan glaukoma sudut tertutup adalah pembedahan. Sebelumnya dilakukan pembedahan sebaiknya dicoba untuk mencegah serangan akut seperti menurunkan TIO terlebih dahulu dengan obat-obatan Medika Mentosa. Jika serangan akut tidak hilang sebaiknya segera lakukan pembedahan secepat mungkin dengan melakukan Laser Iridotomy Periferal, yaitu menggunakan laser untuk membuat 2 drainase lubang kecil pada iris. Ini digunakan untuk menangani kondisi akut dan kronis (Medscape 2016). Penelitian ini dibuat untuk menguraikan salah satu karakteristik penyakit penyebab kebutaan yakni glaucoma sudut tertutup, khususnya faktor risiko apa yang mempengaruhi terjadinya PACG sehingga terjadi kebutaan pada Rumah Sakit Umum Pusat (RSUP) Sanglah.

\section{METODE PENELITIAN}

Rancangan penelitian ini adalah studi cross sectional melalui penelusuran rekam medik. Pemilihan desain studi tersebut didasarkan atas pertimbangan tujuan dari penelitian ini yaitu meneliti faktor resiko kebutaan karena glaukoma pada pasien di Rumah Sakit Umum Pusat Sanglah. Hasil yang diperoleh selanjutnya digambarkan berdasarkan tujuan penelitian yang akan dicapai. Penelitian ini dilaksanakan di ruang Rekam Medis Rumah Sakit Umum Pusat Sanglah Denpasar. Penelitian ini dimulai dari perancangan tema, penyusunan proposal penelitian, pengumpulan data, pengolahan dan analisis data, serta pembuatan laporan hasil penelitian. Penelitian ditargetkan selesai dalam waktu enam bulan, Agustus 2018 - Januari 2019. Populasi Target pada penelitian ini adalah pasien dengan gangguan fungsi mata 
yaitu Glaukoma yang datang ke Rumah Sakit Umum Pusat Sanglah. Populasi terjangkau Sampel penelitian mencakup Pasien Glaukoma Sudut Tertutup dengan data lengkap yaitu usia, jenis kelamin, tekanan intraocular. Pengambilan sampel dilakukan dengan menggunakan total sampling, yaitu dengan mengambil rekam medis pasien Glaukoma dengan Sudut Tertutup di bagian rekam medis Rumah Sakit Umum Pusat Sanglah Denpasar.

\section{ALUR PENELITIAN}

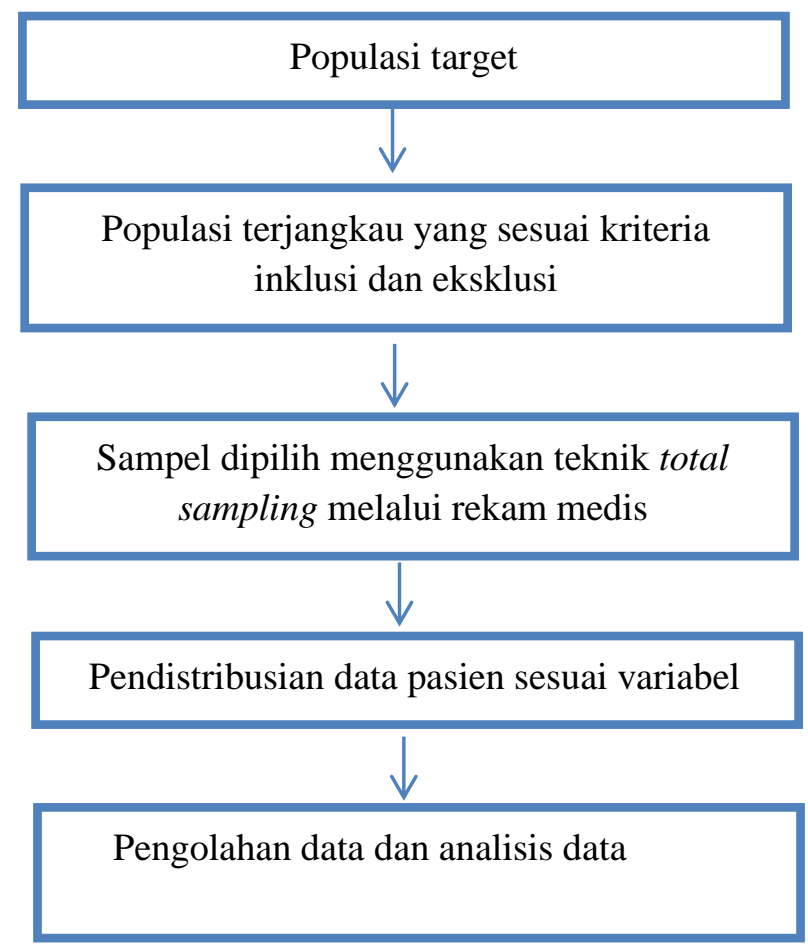

Gambar 1. Alur Penelitian

\section{HASIL PENELITIAN}

Penelusuran data dari identitas dan nomor rekam medis penderita glaucoma sudut tertutup di komputer register pasien periode Juli - Desember tahun 2017 milik Rumah Sakit Umum Pusat Sanglah didapatkan 266 pasien dengan diagnosis glaukoma pada penelusuran ini. Setelah dilakukan penelusuran selama satu bulan, ditemukan adanya 226 rekam medis.
Sebanyak 15 dari 226 rekam medis tersebut tidak dapat digunakan dalam penelitian karena data yang tidak lengkap dan juga rusak untuk dijadikan penelitian. Hasil akhir pencarian rekam medis tersebut, didapatkan sejumlah 211 rekam medis pasien yang dapat dijadikan sebagai subyek penelitian.

Tabel 1 Distribusi penderita Glaukoma dalam 6 bulan tahun 2017

\begin{tabular}{cc}
\hline Bulan & Jumlah Pasien \\
\hline Juli & 41 \\
Agustus & 36 \\
September & 31 \\
Oktober & 33 \\
November & 32 \\
Desember & 38 \\
\hline
\end{tabular}

Insidensi glaucoma sudut tertutup didapatkan sebanyak 4,03\% (211 kasus) dari hasil penelitian di Rumah Sakit Umum Pusat Sanglah. Angka insidensi glaucoma yang cukup tinggi di Rumah Sakit Umum Pusat Sanglah disebabkan sulitnya akses terhadap pelayanan kesehatan. Kesulitan akses pelayanan kesehatan dipengaruhi oleh berbagai faktor seperti tidak adanya kemampuan secara ekonomi karena biaya kesehatan yang mahal, kurangnya pengetahuan masyarakat, faktor teknologi dan ketersediaan tenaga serta fasilitas kesehatan mata yang masih terbatas. 
Tabel 2 Distribusi penderita Glaukoma Berdasarkan Umur

\begin{tabular}{cc}
\hline Usia & Jumlah \\
\hline $0-9$ & 2 \\
$10-19$ & 3 \\
$20-29$ & 14 \\
$30-39$ & 23 \\
$40-49$ & 28 \\
$50-59$ & 50 \\
$60-69$ & 71 \\
$\geq 70$ & 20 \\
\hline
\end{tabular}

Kelompok usia terbanyak yang muncul adalah kelompok usia 60-69 tahun. Kebanyakan penelitian mendapatkan bahwa terdapat korelasi yang positif antara TIO dan usia. Prevalensi glaukoma meningkat dari $1,2 \%$ pada dekade kelima kehidupan, menjadi $7,7 \%$ pada dekade keenam kehidupan. Glaukoma tidak menunjukan gejala saat masih awal dan membuat banyak pasien tidak sadar bahwa mereka memiliki glaukoma. Hal ini menjelaskan mengapa usia terbanyak terjadi pada kelompok usia 60-69 tahun karena gejalanya sudah parah.

Tabel 3 Distribusi penderita Glaukoma berdasarkan jenis kelamin

\begin{tabular}{cc}
\hline Jenis Kelamin & Jumlah \\
\hline Laki - Laki & 112 \\
Perempuan & 99 \\
\hline
\end{tabular}

Distribusi jenis kelamin penderita glaukoma di Rumah Sakit Umum Pusat Sanglah adalah lakilaki sebanyak 112 orang $(51,9 \%)$ dan perempuan sebanyak 99 orang $(48,1 \%)$. Bila disajikan dalam perbandingan maka perbandingan jumlah laki-laki terhadap perempuan adalah 1,08: 1 .

Tabel 4 Distribusi penderita Glaukoma berdasarkan Tekanan Intraokular

\begin{tabular}{cc}
\hline TIO & Jumlah \\
\hline$\geq 21 \mathrm{mmHg}$ & 124 \\
$<21 \mathrm{mmHg}$ & 87 \\
\hline
\end{tabular}

Penderita glaukoma yang memiliki TIO diatas nilai normal (> $21 \mathrm{mmHg}$ ) pada mata sebanyak $64,6 \%$ dan yang dalam rentang nilai normal $(\leq$ $21 \mathrm{mmHg}$ ) sebanyak 35,4\%.

Tabel 5 Distribusi Kebutaan pada Penderita Glaukoma

\begin{tabular}{ccc}
\hline Variabel & Kategori & Buta \\
\hline Usia & $0-39$ & 9 \\
& $40-49$ & 13 \\
& $50-59$ & 22 \\
& $60-69$ & 39 \\
& $\geq 70$ & 15 \\
Jenis Kelamin & Laki - Laki & 38 \\
& Perempuan & 58 \\
Tekanan & $\geq 21$ mmHg & 71 \\
Intraokular & $<21$ mmHg & 27 \\
\hline \multicolumn{3}{c}{ yebutaan } \\
didefinisikan dengan visus/tajam penglihatan \\
<3/60 pada salah satu atau kedua mata. Secara
\end{tabular}


keseluruhan berdasarkan variable usia, jenis kelamin, dan tekanan intraocular didapatkan total pasien buta oleh karena PCAG adalah sebanyak 96 orang dari 211 pasien yang dijadikan sampel penelitian. Kebutaan paling banyak didapatkan pada kelompok umur tertinggi yaitu 60 - 69 tahun yaitu 39 orang. Pada kelompok jenis kelamin didapatkan laki laki lebih sedikit lebih kecil yaitu 38 orang dibandingkan perempuan dengan 58 orang. Kebutaan terlihat lebih banyak dengan peningkatan tekanan intraokuler yaitu 71 orang dibandingkan dengan tekanan intraokuler dalam batas normal yaitu 27 orang.

\section{PEMBAHASAN PENELITIAN}

Sebagian besar pasien glaukoma primer sudut primer di RSUP Sanglah datang dalam kondisi salah satu atau kedua mata telah buta. Didapatkan hubungan yang bermakna antara kebutaan pada pasien glaukoma primer di RSUP Sanglah dengan tekanan intraokular,usia dan jenis kelamin

Berdasarkan tabel 2, Pada Rumah Sakit Umum Pusat Sanglah Denpasar Kelompok usia terbanyak yang muncul adalah kelompok usia 60-69 tahun. Nepal mendapatkan bahwa prevalensi glaukoma terbanyak ditemukan pada kelompok usia 41-60 tahun dan penelitian di Oman mendapatkan bahwa prevalensi glaukoma lebih banyak terjadi pada kelompok usia 40- 49 tahun. Perbedaan ini mungkin disebabkan oleh tidak adanya gejala glaukoma pada tahap awal penyakit dan kurangnya pengetahuan masyarakat di Denpasar sehingga kebanyakan pasien baru menyadarinya setelah usia sudah lanjut.

Berdasarkan tabel 3 diperoleh Distribusi jenis kelamin penderita glaukoma di Rumah Sakit Umum Pusat Sanglah dalam perbandingan jumlah laki-laki terhadap perempuan adalah 1,08: 1. Shekhar et al menemukan perbandingan antara laki-laki dan perempuan sebesar 1,03:1.14. Khandekar et al menemukan perbandingan antara laki-laki dan perempuan sebesar 1,01:1.11 Penelitian yang dilakukan oleh Alan et al mendapatkan prevalensi glaukoma lebih tinggi pada laki-laki dibandingkan pada perempuan, namun perbedaan ini tidak signifikan.

Berdasarkan tabel 4 Penderita glaucoma Pada Rumah Sakit Umum Pusat Sanglah Denpasar yang memiliki TIO diatas nilai normal (> $21 \mathrm{mmHg}$ ) pada mata sebanyak $64,6 \%$ dan yang dalam rentang nilai normal $(\leq$ $21 \mathrm{mmHg}$ ) sebanyak 35,4\%. Penelitian Maharani mendapatkan 56,6\% subyek penelitiannya menderita glaukoma dengan TIO diatas nilai normal dan $43,4 \%$ dalam batas normal. Penderita glaukoma lebih banyak yang memiliki TIO tinggi dibandingkan dengan yang normal berdasarkan data tersebut. Alan et al mendapatkan seluruh sampel penelitian yang menderita glaucoma memiliki TIO $>21 \mathrm{mmHg}$.

Berdasarkan tabel 5 Penderita glaukoma Pada Rumah Sakit Umum Pusat Sanglah Denpasar yang mengalami kebutaan di dapatkan sebanyak $49 \%$ mata dengan visus $<3 / 60$. Penelitian Oktariana, terhadap 360 pasien glaukoma didapatkan $45 \%$ mata dengan visus $\quad<3 / 60$. Penelitian Oktariana, menunjukkan persentase kebutaan yang lebih rendah dibandingkan penelitian ini, kemungkinan karena kasus glaucoma suspect juga dimasukkan dalam populasi penelitian, jika tidak kemungkinan proporsi kebutaan pada penelitian tersebut akan menjadi lebih tinggi.

\section{DAFTAR PUSTAKA}

Broman AT. The number of people with Glaukoma worldwide in 2010 and 2020. British Journal Ophthalmology 2006; 90:262-267.

Shen SY, Wong TY, Foster PJ, et al. The prevalence and types of Glaukoma in Malay people: The Singapore Malay eye study.Investigative Ophthalmology \& Visual Science 2008; 49(9):3846-3851. 
Ilyas S, et al. Ilmu Penyakit Mata untuk Dokter Umum dan Mahasiswa Kedokteran. Sagung Seto Jakarta 2002.

James B, Chew C, Bron A. Lecture Notes on Ophthalmology (edisi terjemah dalam Bahasa Indonesia). Penerbit Erlangga 2006:34-36

Foster PJ, Buhrman R, Quigley HA, et al. The definition and classification of Glaukoma in prevalence surveys. British Journal Ophthalmology 2002;86:238-24

Bourne RRA, Sukudom P, Foster PJ, et al. Prevalence of Glaukoma in Thailand: a population based survey in Rom Klao District, Bangkok. British Journal Ophthalmology 2003;87:1069-1074.

Rahman MM, Rahman N, Foster PJ, et al. The prevalence of Glaukoma in Bangladesh: a population based survey in Dhaka division. British Journal Ophthalmology 2004;88:1493-149

Vijaya L, George R, Arvind H, et al. Prevalence of angle-closure disease in a rural southern Indian population. Arch Ophthalmology 2006; 124:403-409

Buhrmann RR, Quigley HA, Barron Y, et al. Prevalence of Glaukoma in a rural East African population. Invest Ophthalmol Vis Sci. 2000 Jan;41(1):40-8. (abstract)

Departemen Kesehatan Republik Indonesia. Laporan hasil riset kesehatan dasar tahun 2007. Jakarta: Departemen Kesehatan Republik Indonesia; 2008.

Agarwal R, et al. Current concepts in the pathophysiology of Glaukoma. Indian $\mathrm{J}$ Ophthalmol 2009;57: 257-266.

Cronemberger S, Lourenco LFS, Silva LC. Prognosis of Glaukoma in relation to blindness at university hospital. Arc Bras Oftalmol 2009;72(2):199-204.

Stamper RL, Lieberman MF, Drake MV 2009, Becker-Shaffer's Diagnosis and Therapy of the Glaukomas 8th ed., Elsevier 